\title{
Case Report \\ Traumatic Bilateral Pneumothoraces due to Sternal Wire Migration
}

\author{
Umar Imran Hamid, ${ }^{1}$ Scott Gillespie, ${ }^{2}$ Colum Lynchehaun, ${ }^{1}$ and Haralabos Parissis ${ }^{1}$ \\ ${ }^{1}$ Department of Cardiothoracic Surgery, Royal Victoria Hospital, Belfast BT12 6BA, UK \\ ${ }^{2}$ Department of Radiology, Royal Victoria Hospital, Belfast BT12 6BA, UK \\ Correspondence should be addressed to Umar Imran Hamid, umar79@hotmail.com
}

Received 28 January 2012; Accepted 28 March 2012

Academic Editor: T. A. Salerno

Copyright ( 2012 Umar Imran Hamid et al. This is an open access article distributed under the Creative Commons Attribution License, which permits unrestricted use, distribution, and reproduction in any medium, provided the original work is properly cited.

Sternal wound complications after cardiac surgery are associated with increased morbidity and mortality. Wire migrations associated with sternal dehiscence can lead to catastrophic haemorrhage unless intervened in time. We present a case of sternal wire migration causing bilateral pneumothoraces.

\section{Introduction}

Sternal wound complications, including dehiscence and infection, occur in $1 \%$ to $3 \%$ of patients undergoing cardiac surgery. These complications require extended hospitalization, long-term antibiotics and multiple operative procedures, resulting in high financial impact. Various factors affect the risk of sternal wound dehiscence ranging from patient comorbidities to operative techniques. Migrating wires resulting from sternal dehiscence present a clinical challenge and are source of mortality and morbidity.

\section{Case History}

A 67-year-old male presented with a ten-year history of chronic stable angina. Past medical history of significance included coronary artery stenting, bilateral stripping of varicose veins, ulcerative colitis, and previous history of smoking. Coronary angiogram revealed severe left main stem with three vessel disease and preserved left ventricular function. His current medication included aspirin, perindopril, atorvastatin, isosorbide mononitrate, bisoprolol, and azathioprine (for ulcerative colitis). He underwent coronary artery bypass grafts $\times 3$ with left internal mammary artery to left anterior descending artery, right internal mammary artery through the transverse sinus to the marginal branch of the circumflex, and saphenous vein graft to the distal right coronary artery. The immediate postoperative period was uneventful.

He presented 4 weeks later with dry cough and signs of sternal malunion; the sternum was unstable but the overlying skin was intact. Conservative approach with external thoracic support was initially used. He was readmitted two weeks later with persistent cough and acute shortness of breath. Chest roentegram showed laterally displaced sternal wires and bilateral hydro-pneumothoraces (Figure 1). Computed tomography (CT) scan was carried out which confirmed sternal dehiscence (Figure 2).

He subsequently underwent sternal reconstruction. Intraoperatively, the sternum had completely dehisced; an upper left wire and a middle right wire (Figure 3 ) were evident protruding into the respective pleural cavities, coming in to contact with lung parenchyma. A third lower wire was confined between the inferior wall of the right ventricle and the diaphragm, to the right of the midline. After removal of these wires, the sternal edges were refashioned, pectoral muscles mobilised, and Robischek repair was carried out. Bilateral pleural, mediastinal, and subcutaneous drains were placed. The postoperative period was uneventful. At sixthweek followup, his sternum is healing well. 


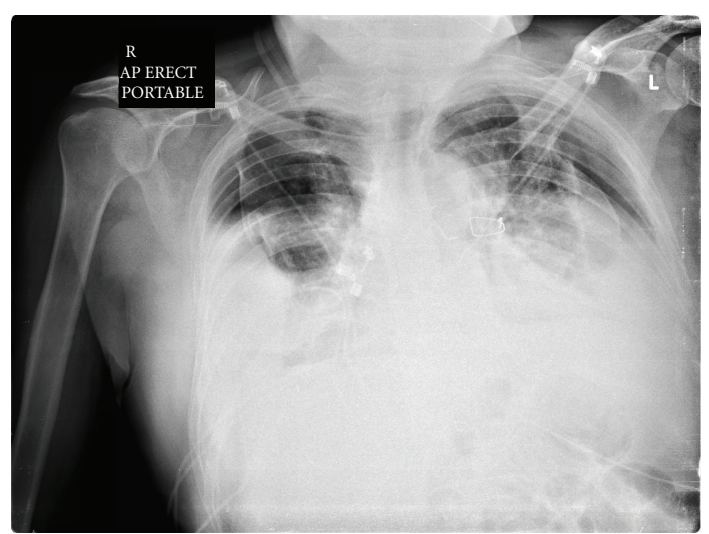

FIGURE 1: CXR showing bilateral pneumothoraces with displaced sternal wires.

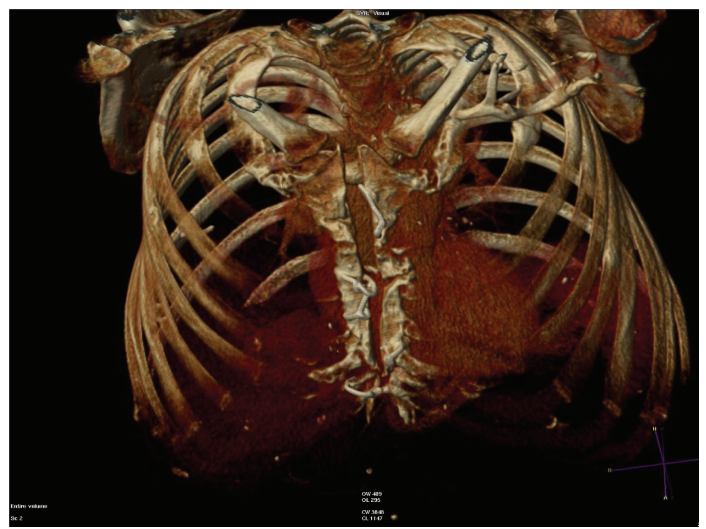

FIgURE 2: CT reconstruction of sternal dehiscence.

\section{Discussion}

Sternal wound complications after median sternotomy are infrequent and can be potentially devastating leading to morbidity and mortality [1].

Obesity, female sex, diabetic disease, bilateral internal mammary artery harvesting, postoperative renal failure, and prolonged ventilation are known factors that increase the risk of sternal complications $[2,3]$. Harvesting of internal mammary artery (IMA) for coronary artery bypass grafting (CABG) can lead to decreased circulation to the sternum [4]. Caution should be exercised in patients on immunosuppressive drugs such as steroids and azathioprine who already have impaired wound healing while considering bilateral internal mammary artery harvesting.

Pain is the most frequent symptom encountered with sternal malunion. Some patients may be incapacitated by discomfort associated with fractured wires or nonunion. Others tolerate varying degrees of discomfort to avoid further operation.

Sternal wire migration is usually treated conservatively unless complications occur. Various complications of sternal wire migration have been published in the literature, including tamponade resulting from right ventricular injury

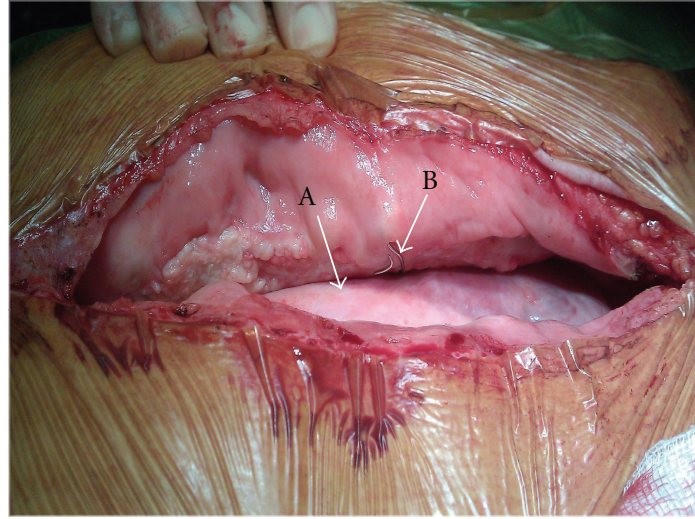

FIGURE 3: Intraoperative pictures of sternal dehiscence with Lung parenchyma (Arrow A) coming in contact with sternal wire (Arrow B).

[5], aortic injury [6], hemoptysis [7], and pulmonary valve endocarditis [8]. Right Ventricular laceration due to sternal wire migration is associated with mortality of up to $50 \%$.

Migrated sternal wires should be assessed by radiological imaging to ascertain the potential risk of mediastinal injury. CT angiography allows precise and reproducible localization of vital mediastinal structures. When planning sternal reconstruction, CT scan can give important information concerning exact spatial location of conduits and proximity of cardiac chambers to the sternum, as well as location of sternal wires.

Bilateral pneumothoraces, on a background of sternal wire displacement, prompted us to proceed with urgent surgery. Radiological and intraoperative findings were consistent with sternal dehiscence and displaced sternal wires in proximity to lung parenchyma. The wires, on a background of persistent dry cough, could have account for direct lung injury with subsequent traumatic pneumothoraces.

In conclusion, sternal wire migration can be associated with fatal mediastinal injury. The intraoperative and postoperative management should be individualized to minimize sternal complications. Patients who have migrated wires should have radiological assessment to determine proximity to vital structures and be managed accordingly.

\section{References}

[1] T. Ivert, D. Lindblom, J. Sahni, and J. Eldh, "Management of deep sternal wound infection after cardiac surgery-Hanuman syndrome," Scandinavian Journal of Thoracic and Cardiovascular Surgery, vol. 25, no. 2, pp. 111-117, 1991.

[2] E. Ståhle, A. Tammelin, R. Bergström, A. Hambreus, S. O. Nyström, and H. E. Hansson, "Sternal wound complicationsIncidence, microbiology and risk factors," European Journal of Cardio-thoracic Surgery, vol. 11, no. 6, pp. 1146-1153, 1997.

[3] J. C. Y. Lu, A. D. Grayson, P. Jha, A. K. Srinivasan, and B. M. Fabri, "Risk factors for sternal wound infection and mid-term survival following coronary artery bypass surgery," European Journal of Cardio-thoracic Surgery, vol. 23, no. 6, pp. 943-949, 2003. 
[4] M. Lorberboym, B. Medalion, O. Bder et al., "99mTc-MDP bone SPECT for the evaluation of sternal ischaemia following internal mammary artery dissection," Nuclear Medicine Communications, vol. 23, no. 1, pp. 47-52, 2002.

[5] J. Levisman, R. J. Shemin, J. M. Robertson, P. Pelikan, and R. P. Karlsberg, "Migrated sternal wire into the right ventricle: case report in cardiothoracic surgery," Journal of Cardiac Surgery, vol. 25, no. 2, pp. 161-162, 2010.

[6] S. R. Hazelrigg and B. Staller, "Migration of sternal wire into ascending aorta," Annals of Thoracic Surgery, vol. 57, no. 4, pp. 1023-1024, 1994.

[7] A. J. Schreffler and J. D. Rumisek, "Intravascular migration of fractured sternal wire presenting with hemoptysis," Annals of Thoracic Surgery, vol. 71, no. 5, pp. 1682-1684, 2001.

[8] S. S. Bhavani, W. Slisatkorn, S. J. Rehm, and G. B. Pettersson, "Deep sternal wire infection resulting in severe pulmonary valve endocarditis," Annals of Thoracic Surgery, vol. 82, no. 3, pp. 1111-1113, 2006. 


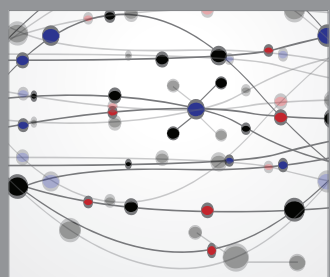

The Scientific World Journal
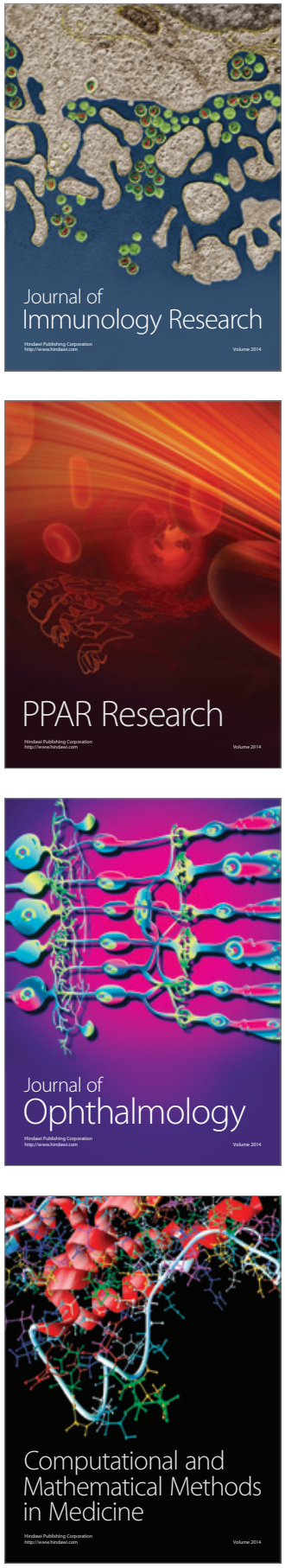

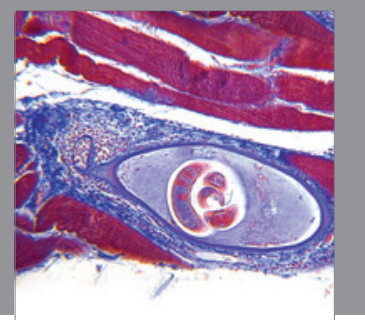

Gastroenterology

Research and Practice
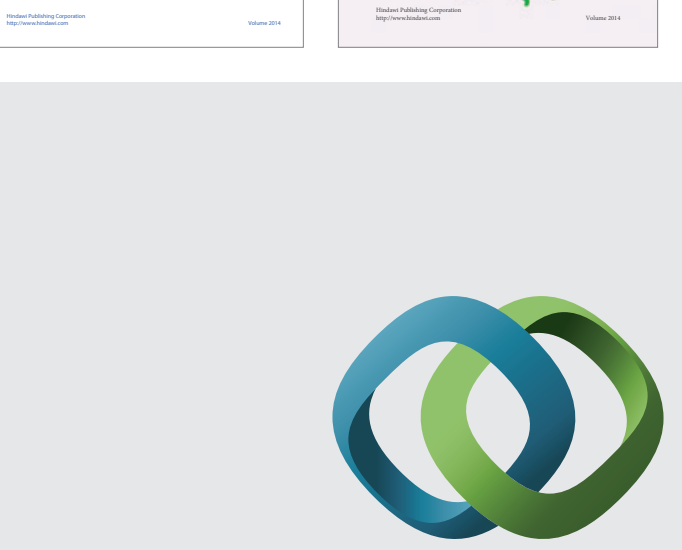

\section{Hindawi}

Submit your manuscripts at

http://www.hindawi.com
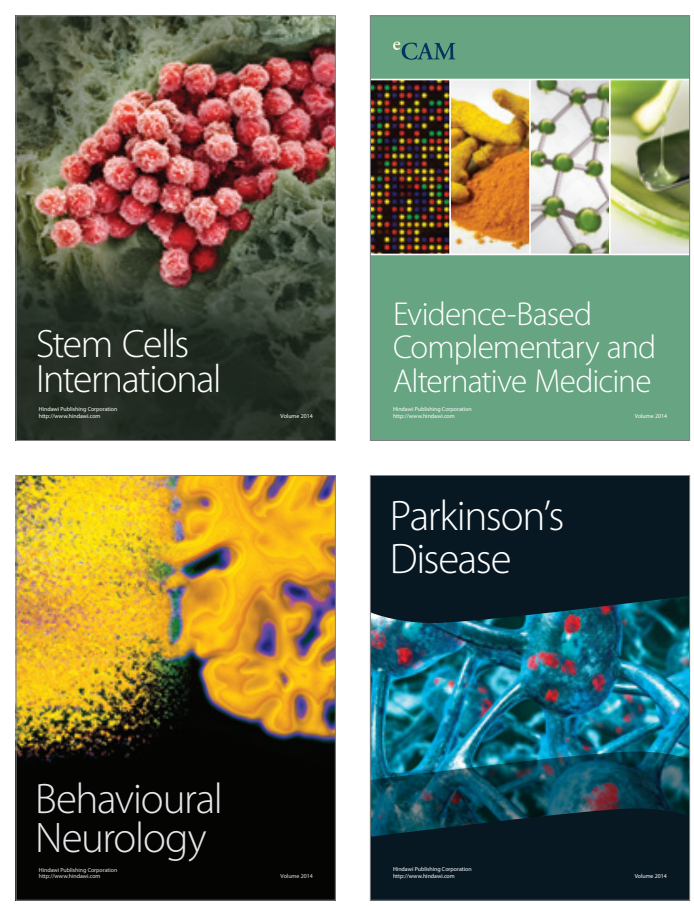

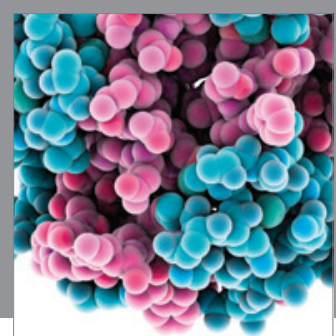

Journal of
Diabetes Research

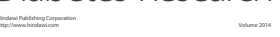

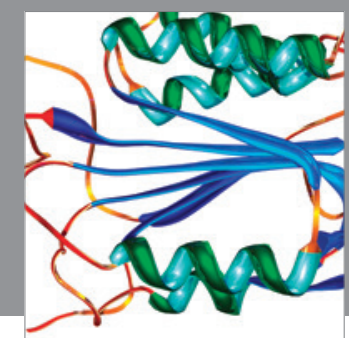

Disease Markers
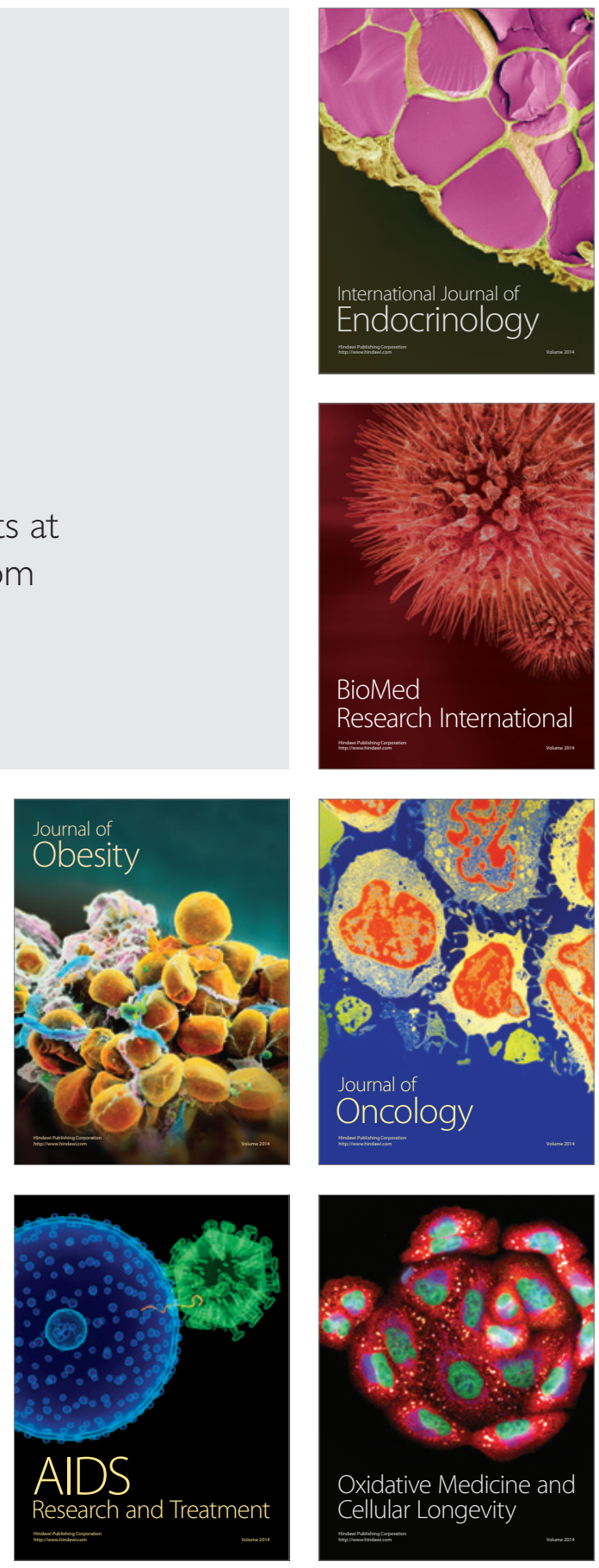